\title{
Ligand-Induced Structural, Photophysical, and Electrochemical Variations in Tricarbonyl Rhenium(I) Tetrazolato Complexes
}

\author{
Phillip J. Wright, ${ }^{\dagger}$ Mark G. Affleck, ${ }^{\dagger}$ Sara Muzzioli, ${ }^{\ddagger}$ Brian W. Skelton, ${ }^{\S}$ Paolo Raiteri, ${ }^{\dagger}$ Debbie S. Silvester, ${ }^{\dagger}$ \\ Stefano Stagni, ${ }^{*}{ }^{\ddagger}$ and Massimiliano Massi ${ }^{*}{ }^{\dagger}$ \\ ${ }^{\dagger}$ Department of Chemistry, Curtin University, Kent Street, Bentley 6102 WA, Australia \\ ${ }^{\ddagger}$ Department of Industrial Chemistry “Toso Montanari”, University of Bologna, Viale del Risorgimento 4, Bologna 40126, Italy \\ ${ }^{\S}$ Centre for Microscopy, Characterisation and Analysis, University of Western Australia, Crawley 6009 WA, Australia
}

Supporting Information

ABSTRACT: Treatment of $\left[\operatorname{Re}(\mathrm{CO})_{5} \mathrm{X}\right](\mathrm{X}=\mathrm{Cl}, \mathrm{Br})$ with 2(2-tert-butyltetrazol-5-yl)pyridine yielded neutral mononuclear complexes by exchange of two $\mathrm{CO}$ ligands for the chelating tetrazolato ligand. Treatment of $\left[\operatorname{Re}(\mathrm{CO})_{5} \mathrm{Br}\right]$ with phenyltetrazolate resulted in the assembly of an anionic dinuclear rhenium tricarbonyl species bridged by three tetrazole rings. The reaction of $\left[\operatorname{Re}(\mathrm{CO})_{5} \mathrm{Br}\right]$ with (2-tert-butyltetrazol-5yl)benzene formed an analogous neutral dinuclear complex bridged by a tetrazole ring as well as two bromide ligands; however this complex was found to be rather unstable in

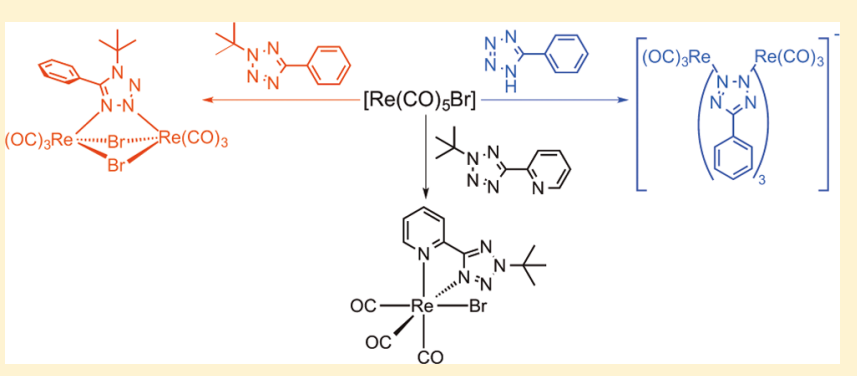
solution and was only structurally characterized via X-ray diffraction. The first three complexes were investigated for their photophysical properties, highlighting phosphorescent emission from their triplet metal-to-ligand charge transfer excited states, although in the case of the dinuclear species the quantum yield was found to be extremely low. The complexes are also characterized for their electrochemical behavior, and while the neutral mononuclear species show irreversible oxidations, the dinuclear complex displays one reversible and simultaneous two-electron oxidation.

\section{INTRODUCTION}

Emissive tricarbonyl rhenium(I) complexes of formulation fac$\left[\operatorname{Re}(\mathrm{CO})_{3}(\operatorname{diim}) \mathrm{L}\right]^{0 /+}$, where $\operatorname{diim}$ represents a neutral chelating diimine-type ligand such as $2,2^{\prime}$-bipyridine and $\mathrm{L}$ a neutral or anionic monodentate ancillary ligand, have been the focus of intense investigation. ${ }^{1,2}$ The interest in these complexes largely stems from their favorable photophysical properties that make them amenable to a variety of areas, from the fabrication of organic light-emitting devices to cellular labeling. ${ }^{3-7}$ The photophysics of these species has now been well established, and their emissive properties are in general attributed to a spin-forbidden radiative decay originating from excited states possessing a triplet metal-to-ligand charge transfer character $\left[{ }^{3} \mathrm{MLCT} ; 5 \mathrm{~d}(\mathrm{Re}) \rightarrow \pi^{*}(\mathrm{diim})\right] .{ }^{8-12}$ This excited state can sometimes be mixed with excited states of ligandcentered (LC) origin, such as $\pi-\pi^{*}$ transitions localized on the diim ligand, or of ligand-to-ligand charge transfer character [LLCT; $\mathrm{L} \rightarrow \pi^{*}($ diim $\left.)\right]$ when the ancillary ligand is a halogen or electron-rich species. ${ }^{1,12}$ The photophysical features of these complexes, in terms of absorption and emission maxima, can be readily tuned by opportune chemical modifications on the diim and/or L ligands. ${ }^{1,2}$ Rendering the diim ligand more electronrich or electron-poor directly manipulates the energy of the LUMO, thus inducing a hypsochromic or bathochromic shift, respectively. On the other hand, electron-rich anionic ancillary ligands destabilize the $5 \mathrm{~d}$ orbitals of the Re center, lowering the energy of the MLCT manifold, whereas neutral electronwithdrawing ligands raise the energy of the MLCT manifold. The variation of the relative energy of the emissive ${ }^{3}$ MLCT has also profound consequences on the photophysical performance in terms of quantum yield $(\Phi)$ and excited-state lifetime $(\tau)$ of these rhenium complexes, a trend that is found in general agreement with the energy gap law. ${ }^{13}$ Therefore, positively charged complexes with electron-withdrawing ancillary ligands (e.g., pyridine) have generally a higher quantum yield and longer excited-state lifetime compared to neutral complexes, which is the consequence of a lower nonradiative decay constant $\left(k_{\mathrm{nr}}\right)$ for the former due to a larger energy gap between the ${ }^{3}$ MLCT excited state and the ground state. ${ }^{1,13}$ Despite this trend, highly emissive blue rhenium complexes (e.g., $\lambda_{\text {em }}<450 \mathrm{~nm}$ ) are extremely rare since as the energy of the ${ }^{3}$ MLCT increases, the thermal population of quenching excited states becomes progressively more efficient. ${ }^{14}$

We have been interested in the photophysical properties of mononuclear and dinuclear tricarbonyl rhenium(I) tetrazolato complexes, and we have recently reported the indirect influence of the tetrazolato ancillary ligand in governing the relative energy of the ${ }^{3} \mathrm{MLCT}\left[5 \mathrm{~d}(\mathrm{Re}) \rightarrow \pi^{*}(\mathrm{diim})\right]$ excited states via stabilization or destabilization of the $5 \mathrm{~d}$ orbitals of the rhenium

Received: April 24, 2013

Published: June 17, 2013 


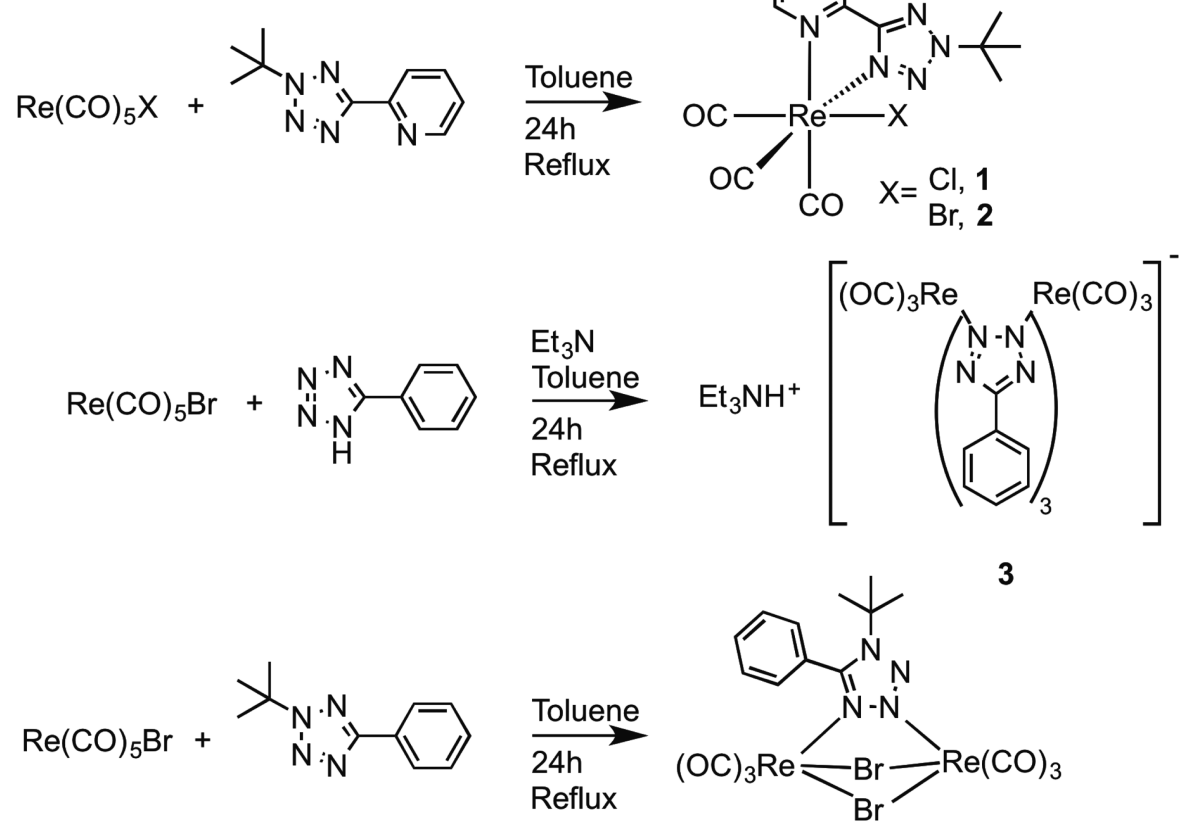

Figure 1. Synthesis of the complexes reported in this work.

centers. ${ }^{15,16}$ Furthering these studies, we have sought rhenium tetrazolato complexes of alternative nature, so that the tetrazolato ligand is directly involved in the MLCT excited state, in a similar fashion to what we have previously reported in the case of sky-blue-emitting platinum(II) complexes $^{17}$ and what others have reported for rhenium(I) complexes bound to triazoles. ${ }^{18-23}$ To achieve this goal, we have tried to synthesize complexes of analogous formulation to $\mathrm{fac}$ - $\left[\operatorname{Re}(\mathrm{CO})_{3}(\operatorname{diim})\right.$ $\mathrm{L}]^{0 /+}$, where the diim ligand is substituted by a chelating aryltetrazolato ligand. Our first attempt resulted in the serendipitous formation of a metallacalix[3] arene by treatment of $\left[\operatorname{Re}(\mathrm{CO})_{5} \mathrm{X}\right](\mathrm{X}=\mathrm{Cl}, \mathrm{Br})$ with 2-pyridyltetrazolate, which is characterized by a relatively efficient aqua-colored emission, demonstrating the direct involvement of the tetrazolato ligand in the ${ }^{3}$ MLCT excited state. ${ }^{24}$ As a continuation of this work, we now report the complexes obtained by treating $\left[\operatorname{Re}(\mathrm{CO})_{5} \mathrm{X}\right]$ $(\mathrm{X}=\mathrm{Cl}, \mathrm{Br})$ with the neutral tert-butylated phenyl- and pyridyltetrazole as well as the anionic phenyltetrazolate (Figure 1 ). While in the case of the neutral tert-butylated pyridyltetrazole the expected mononuclear tricarbonyl of facial arrangement is isolated, for the remaining ligands we isolated dinuclear structures bridged by three phenyltetrazolato ligands or by one tert-butylated phenyltetrazole and two bromide ligands. The diverse photophysical and electrochemical properties of these species were also investigated and corroborated by computational calculations.

\section{RESULTS AND DISCUSSION}

Synthesis and Characterization. The tetrazole ligands, 2(1H-tetrazol-5-yl)pyridine and 5-phenyl-1H-tetrazole, were synthesized via a 1,3-dipolar cycloaddition of $\mathrm{NaN}_{3}$ to the corresponding aryl nitriles, according to previously published procedures. $^{25}$ The tert-butylation of the tetrazole rings was performed by treating the corresponding substrates with sulfuric acid or in the case of $2-(1 H$-tetrazol-5-yl)pyridine with additional trifluoroacetic acid, in tert-butyl alcohol. ${ }^{16}$

The preparation of the complexes $\mathbf{1}$ and $\mathbf{2}$ was achieved by reaction of $\left[\operatorname{Re}(\mathrm{CO})_{5} \mathrm{X}\right](\mathrm{X}=\mathrm{Cl}, \mathrm{Br})$ with 2-(2-tertbutyltetrazol-5-yl)pyridine in refluxing toluene, as shown in Figure 1. Both of these complexes were structurally characterized by X-ray diffraction, and their structural formulation appeared consistent by means of IR and NMR spectroscopy as well as elemental analysis. In particular, the IR spectra reveal the presence of three carbonyl bands (with the two lower frequency bands overlapping), as expected from a tricarbonyl rhenium complex of facial arrangement and belonging to the $C_{1}$ point group, as further confirmed in the presence of three distinct peaks in the ${ }^{13} \mathrm{C}$ NMR spectra corresponding to the $\mathrm{CO}$ ligands.

Complex 3 was obtained by reaction of $\left[\operatorname{Re}(\mathrm{CO})_{5} \mathrm{Br}\right]$ with 5phenyltetrazolate in refluxing toluene, as shown in Figure 1. The X-ray structural determination revealed an anionic dinuclear species counterbalanced by a triethylammonium cation. This motif was further supported by means of IR and NMR spectroscopy as well as elemental analysis. The ${ }^{1} \mathrm{H}$ NMR spectrum evidences a 1:3 ratio between the triethylammonium cation and the tetrazole ligands of the dinuclear anionic complex. The ${ }^{13} \mathrm{C}$ NMR shows the presence of one single peak at $196.6 \mathrm{ppm}$ corresponding to the six CO ligands, suggesting the equivalence of these six ligands. Also, the signal at 167.0 ppm assigned to the tetrazolic $\mathrm{C}$ atom is typical of extended conjugation between the tetrazole and the phenyl ring, which can only be achieved through a coplanar arrangement of the two rings. ${ }^{26-29}$ The IR spectrum highlights two bands in the carbonyl fingerprint region at 2024 and $1901 \mathrm{~cm}^{-1}$, suggesting either a $D_{3 h}$ point group for the entire assembly or two noninteracting rhenium tricarbonyl fragments of $C_{3 v}$ symmetry. Noteworthy, there was no evidence of formation of the same dinuclear species when the reaction was attempted starting 

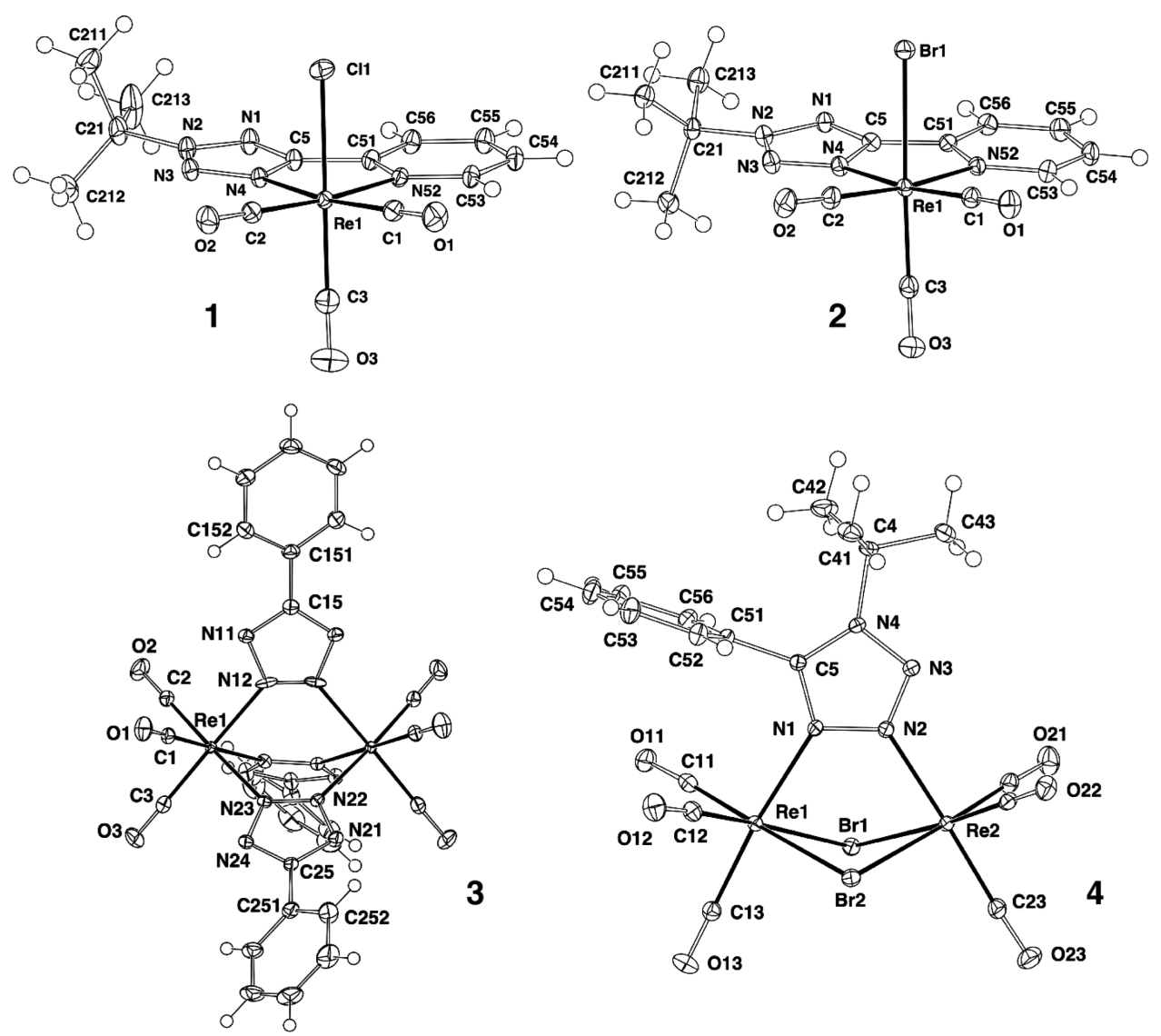

Figure 2. X-ray crystal structures of the complexes, with ellipsoids drawn at the $50 \%$ probability level. Solvent molecules and the triethylammonium cation in the case of 3 are omitted for clarity.

from $\left[\operatorname{Re}(\mathrm{CO})_{5} \mathrm{Cl}\right]$ instead of $\left[\operatorname{Re}(\mathrm{CO})_{5} \mathrm{Br}\right]$, hinting to the fact that the higher lability of the bromide ligand might be favoring the dinuclear assembly by displacement with the negatively charged tetrazolato ligand. Assemblies with loss of two $\mathrm{CO}$ and a bromide ligand have in fact been reported by treatment of $\left[\operatorname{Re}(\mathrm{CO})_{5} \mathrm{Br}\right]$ with anionic ligands such as 2-pyridyltetrazolate or monothiobenzoate. ${ }^{24,30}$

In an attempt to obtain a cyclometalated rhenium(I) complex, (2-tert-butyltetrazol-5-yl)benzene was combined with $\left[\operatorname{Re}(\mathrm{CO})_{5} \mathrm{Br}\right]$ in refluxing toluene (Figure 1). While single crystals could be grown, the bulk was always found contaminated with other unidentified products that could not be easily removed. Furthermore, the compound does not seem to be stable over time in solution, as witnessed by changes occurring in the NMR spectra, a behavior that was observed before for dinuclear rhenium(I) complexes of analogous structures bound to 1,2-diazine bridging ligands. ${ }^{7}$ Despite the lack of purity, the ${ }^{1} \mathrm{H}$ NMR spectroscopic data seem to be in agreement with the structural details obtained via X-ray diffraction. Only a structural investigation is provided within this work. Interestingly, the structure of $\mathbf{4}$ is again a dinuclear complex with an arrangement analogous to complex 3 , but this time the two bromide ligands are retained in the structure. The presence of the bridging halogens reinforces the argument that their displacement is favored by anionic ligands, such as 5phenyltetrazolate in the case of 3 , but not when the pentacarbonyl precursor is treated with neutral ligands such as (2-tert-butyltetrazol-5-yl)benzene. The same trend is observed by previously published dinuclear complexes of analogous structures reported by others. ${ }^{731-33}$ Remarkably, the analysis of the structure of complex 4 shows that a migration of the tert-butyl group occurred, which moved from its original position on the $\mathrm{N} 2$ atom to the $\mathrm{N} 1$ atom of the tetrazole ring. While we have previously reported migration of the rhenium fragment between the $\mathrm{N} 1$ and $\mathrm{N} 2$ atoms of a tetrazolato ligand, ${ }^{16}$ the migration of an alkyl group has never been previously observed in our studies. However, it should be noted that while the alkylation of the tetrazole ligand was generally achieved using a methyl substituent, ${ }^{29,34}$ in this case the higher stability of the tert-butyl cation could be taken into account to rationalize the migration. A space-fill analysis of the structure reveals that without the $\mathrm{N} 2$ to $\mathrm{N} 1$ migration of the tert-butyl substituent the structure would not form due to steric hindrance between the alkyl group and the close CO ligands. Furthermore, the N1 tert-butylation causes the rotation of the phenyl ring of ca. $90^{\circ}$ with respect to the tetrazole ring. Again, this rotation is necessary to accommodate the phenyl ring close to the CO ligands.

X-ray Structural Determination. The structures of the prepared complexes are shown in Figure 2 (see Supporting Information for bond lengths and angles tables). For the mononuclear complexes, 1 crystallizes in the monoclinic space group $P 2_{1} / n$, and 2 crystallizes in the monoclinic space group $P 2_{1} / c$. Both complexes have an analogous octahedral coordination around the metal centers with the three $\mathrm{CO}$ ligands in a facial configuration. In both crystal structures, the tert-butyl substituent is connected to the $\mathrm{N} 2$ atom of the tetrazole ring, while the rhenium coordinates to the $\mathrm{N} 4$ atom. No evidence of the other possible linkage isomer where the tertbutyl is attached to the $\mathrm{N} 2$ atom and the rhenium is 
Table 1. Summary of the Photophysical Data

\begin{tabular}{|c|c|c|c|c|c|c|c|c|}
\hline & absorption & \multicolumn{5}{|c|}{ emission, $298 \mathrm{~K}$} & \multicolumn{2}{|c|}{ emission, $77 \mathrm{~K}$} \\
\hline & $\lambda_{\mathrm{ab}}\left(10^{4} \varepsilon\right)\left[\mathrm{nm}\left(\mathrm{M}^{-1} \mathrm{~cm}^{-1}\right)\right]$ & $\lambda_{\mathrm{em}}[\mathrm{nm}]$ & $\tau^{a}[\mathrm{~ns}]$ & $\tau^{b}[\mathrm{~ns}]$ & $\Phi^{a}$ & $\Phi^{b}$ & $\lambda_{\mathrm{em}}[\mathrm{nm}]$ & $\tau[\mu \mathrm{s}]$ \\
\hline 1 & $\begin{array}{l}271(1.4) \\
353(0.4)\end{array}$ & 574 & 167 & 291 & 0.033 & 0.077 & 510 & 5.81 \\
\hline 2 & $\begin{array}{l}268(1.1) \\
358(0.3)\end{array}$ & 568 & 177 & 323 & 0.024 & 0.058 & 508 & 6.28 \\
\hline 3 & $\begin{array}{l}253(6.85) \\
312(0.6)\end{array}$ & $\begin{array}{l}354 \\
515\end{array}$ & 10 & 12 & $-{ }^{c}$ & $-^{c}$ & 474 & 4.30 \\
\hline
\end{tabular}

${ }^{a}$ From air-equilibrated solution. ${ }^{b}$ From degassed solution. ${ }^{c}$ Value too low to be accurately determined.

coordinated to the $\mathrm{N} 1$ atom was found. This isomer is probably not formed due to the steric hindrance caused by the vicinity of the tert-butyl substituent and the CO ligand.

The dinuclear anionic complex 3 crystallizes in the monoclinic space group $C 2 / c$. The two metal centers are bridged by the tetrazole rings of three ligands, binding to the $\mathrm{N} 2$ and $\mathrm{N} 3$ atoms of each ligand respectively with an $\mu_{2^{-}}$ $\eta^{1}(\mathrm{~N} 2): \eta^{1}(\mathrm{~N} 3)$ arrangement, resembling the bonding motif that is commonly encountered in the structures of several tetrazolate and tetrazole-based MOFs. ${ }^{35-37}$ There are water molecules present in the lattice that are hydrogen bonded to the triethylammonium cations. In the solid state, it seems that the coplanarity between the tetrazole and phenyl rings is lost, with twisting angles of ca. $16^{\circ}, 34^{\circ}$, and $32^{\circ}$. While the direction of the twisting is the same and would cause helical chirality to the species, this rotation is likely to be lost in solution. The distance between the two rhenium centers is ca. $4.0 \AA$; thus the presence of a $\mathrm{Re}-\mathrm{Re}$ bond can be excluded. ${ }^{31}$

The dinuclear complex 4 crystallizes in the monoclinic space group $P 2_{1} / n$. The structure is analogous to complex 3 , with the tetrazole ligands coordinated in a $\mu_{2}-\eta^{1}(\mathrm{~N} 3): \eta^{1}(\mathrm{~N} 4)$ fashion and the two bridging bromide ligands. The Re $\cdots$ Re separation of ca. $3.7 \AA$ again excludes the presence of any $\mathrm{Re}-\mathrm{Re}$ bond. ${ }^{31}$

Photophysical Properties. A summary of the photophysical data can be found in Table 1, and the individual absorption and emission profiles from dilute air-equilibrated dichloromethane solutions ( $\mathrm{ca} .10^{-5} \mathrm{M}$ ) can be found in Figure 3 (see Supporting Information for the excitation profiles and emission profiles measured at $77 \mathrm{~K}$ ).

The complexes $\mathbf{1}$ and $\mathbf{2}$ appear to have almost identical absorption profiles, generally displaying an intense band in the 250-280 nm region and a lower energy band of reduced intensity peaking around $355 \mathrm{~nm}$. The higher energy band is attributed to the spin-allowed LC transition localized on the tetrazole chelating ligand. The lower energy band is, on the other hand, attributed to the spin-allowed MLCT transition $\left[5 \mathrm{~d}(\operatorname{Re}) \rightarrow \pi^{*}\right.$ (pyridyltetrazole $\left.)\right]$.

For compound 3 the absorption profile has an intense highenergy band at $253 \mathrm{~nm}$, which tails off to a lower energy shoulder at $312 \mathrm{~nm}$. The peak at $250 \mathrm{~nm}$ is attributed to the LC transition localized on the 5-phenyltetrazolate ligand. The lower energy shoulder is attributed to an MLCT manifold, and this conclusion is corroborated by the fact that an absorption spectrum of phenyltetrazolate is characterized by the intense band around $250 \mathrm{~nm}$ without any shoulder. Due to the proximity of these excited states, the band is probably a convoluted admixture of LC/MLCT transitions. ${ }^{12}$ The blueshifted MLCT of 3 with respect to those of $\mathbf{1}$ and $\mathbf{2}$ might be ascribed to a higher energy of the empty $\pi^{*}$ orbitals of phenyltetrazolate with respect to the pyridyltetrazole system,

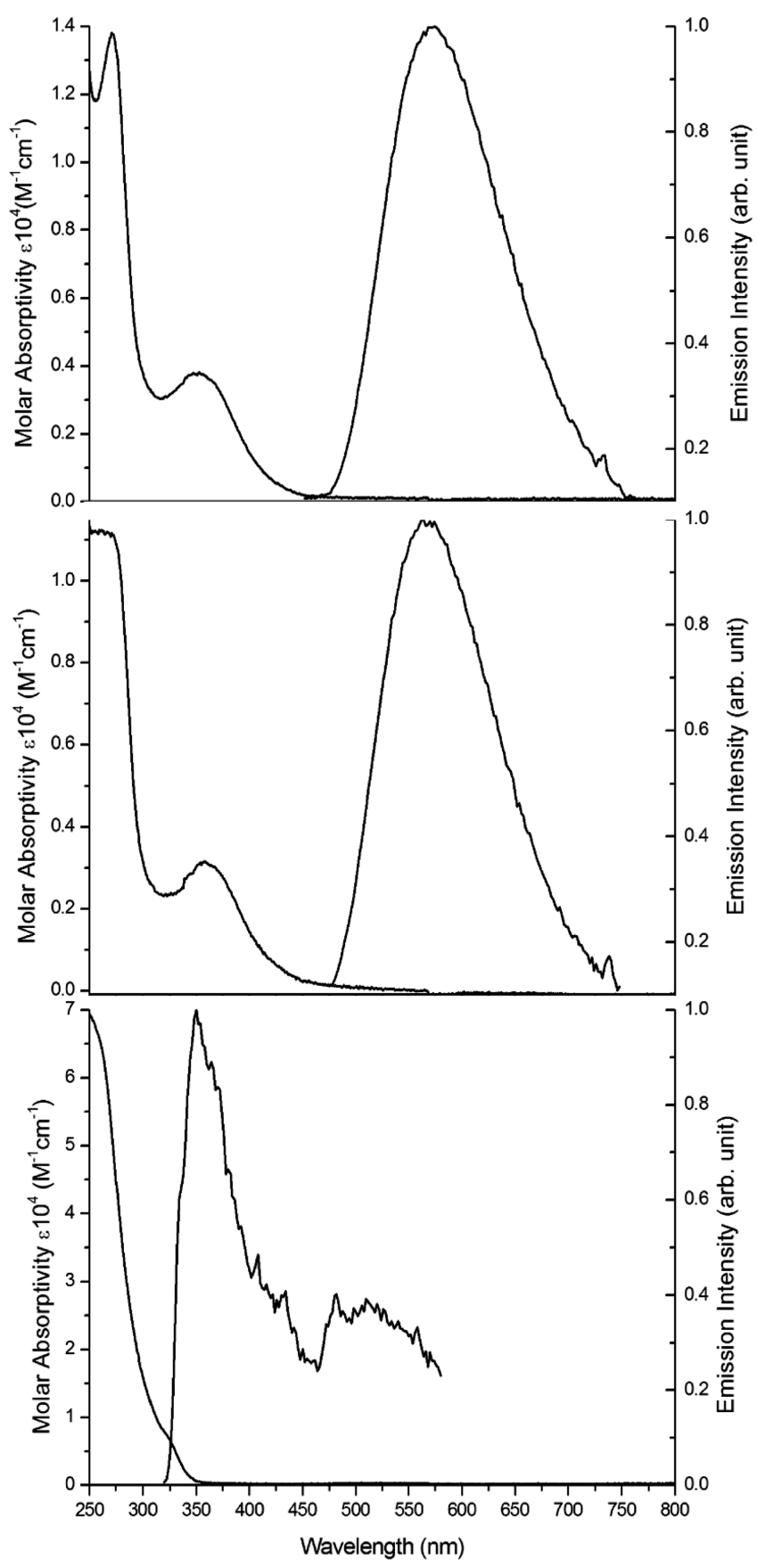

Figure 3. Absorption and normalized emission profiles for 1 (top), 2 (middle), and 3 (bottom) from diluted (ca. $10^{-5} \mathrm{M}$ ) dichloromethane solutions at room temperature. 
the latter further stabilized by the coordination of the metal center to both the tetrazole and pyridine ring.

For complexes 1 and 2, following excitation to the singlet manifolds and internal conversion to the lowest singlet excited state, the corresponding triplet manifold is populated via intersystem crossing. ${ }^{1}$ The radiative decay from this excited state produces similar broad and structureless emission profiles centered at $\lambda_{\mathrm{em}}=574$ and $568 \mathrm{~nm}$ for 1 and 2, respectively. The emission profiles are typical of excited states characterized by a charge transfer nature, and they are independent from the excitation wavelength. The excited-state lifetime decays $(\tau)$ are monoexponential for both cases, with values suggesting phosphorescent emission from excited states of triplet multiplicity $\left({ }^{3}\right.$ MLCT). The lifetime and quantum yield $(\Phi)$ values in air-equilibrated and degassed solutions show that the excited states are partially quenched by the presence of oxygen, consistently with their triplet multiplicity. In a rigid matrix at 77 $\mathrm{K}$ there is a significant hypsochromic shift in the emission maxima of ca. $60 \mathrm{~nm}$ caused by rigidochromism. The band at $77 \mathrm{~K}$ remains structureless, suggesting a lack of mixing with excited states of LC nature. ${ }^{1}$

Complex 3 exhibits a very weak, short-lived $(\tau \approx 10 \mathrm{~ns})$, and almost $\mathrm{O}_{2}$-insensitive emission in dichloromethane solution at room temperature. This could be due to the efficient population of quenching higher excited states as a consequence of the blue-shifted lower-lying MLCT states, ${ }^{12,14}$ as evidenced on comparing the absorption spectra of $\mathbf{1}$ and $\mathbf{2}$ with that of $\mathbf{3}$, or by low-frequency vibrations of the assembly. The complex is also weekly emissive at $77 \mathrm{~K}$, from where a low-intensity structured band can be detected, suggesting mixing of MLCT and LC excited states. ${ }^{1}$

Electrochemical Properties. The electrochemical behavior of the complexes was investigated using cyclic voltammetry, and a summary of the data can be found in Table 2 . The

Table 2. Summary of the Electrochemical Data $\left(E_{\mathrm{p}}=\right.$ peak potential, $\Delta E_{\mathrm{pp}}$ = peak-to-peak separation)

\begin{tabular}{|c|c|c|c|c|}
\hline & \multicolumn{2}{|c|}{ oxidation peak } & \multicolumn{2}{|c|}{ reduction peak } \\
\hline & $E_{\mathrm{p}}$ vs $\mathrm{Fc} / \mathrm{Fc}^{+}(\mathrm{V})$ & $\Delta E_{\mathrm{pp}}(\mathrm{mV})$ & $E_{\mathrm{p}}$ vs $\mathrm{Fc} / \mathrm{Fc}^{+}(\mathrm{V})$ & $\Delta E_{\mathrm{pp}}(\mathrm{mV})$ \\
\hline 1 & 1.04 & $-^{a}$ & -1.89 & 110 \\
\hline 2 & 1.03 & $--^{a}$ & -1.88 & 110 \\
\hline 3 & 1.10 & 80 & -1.62 & $-^{a}$ \\
\hline
\end{tabular}

${ }^{a}$ Peak-to-peak separations could not be elucidated due to the irreversible nature of the voltammetry.

voltammograms were recorded from solutions of the complexes in the ionic liquid 1-hexyl-3-methylimidazolium tris(pentafluoroethyl)trifluorophosphate, $\left[\mathrm{C}_{6} \mathrm{mim}\right][\mathrm{FAP}]$, whose advantages have been previously described in our work. ${ }^{16,38}$

The voltammetric curves can be seen in Figure 4 for the oxidation region and Figure 5 for the reduction region. For complexes 1 and 2, the oxidation potentials are at 1.04 and 1.03 $\mathrm{V}$, respectively, and are attributed to the oxidation occurring on the rhenium center, $\operatorname{Re}(\mathrm{I}) \rightarrow \operatorname{Re}(\mathrm{II})+\mathrm{e}^{-}$, following electrochemical studies reported on analogous neutral mononuclear complexes $f a c-\left[\operatorname{Re}(\mathrm{CO})_{3}(\operatorname{diim}) \mathrm{L}\right]{ }^{39}$ The oxidation peaks appear to have no reversible character at $100 \mathrm{mV} \mathrm{s}^{-1}$, and potentially occurring follow-up chemistry appears to be very fast on the voltammetric time scale. Similar irreversible oxidation peaks were observed for tricarbonyl $\operatorname{Re}(\mathrm{I})$ complexes bound to the analogous pyridyltriazolato ligands. ${ }^{40}$ On the other hand, the oxidation process of $\mathbf{3}$ is characterized by a

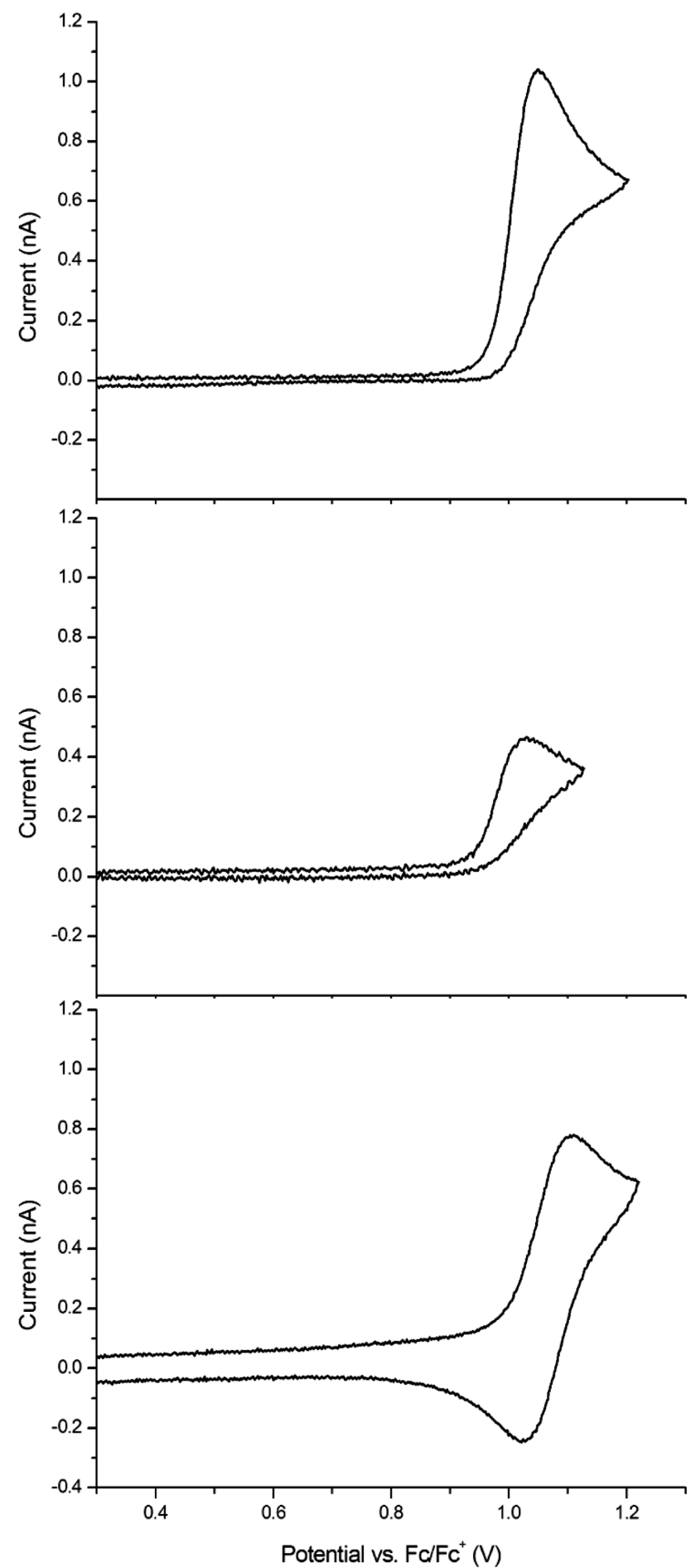

Figure 4. Oxidation range of the cyclic voltammograms for solutions of 1 (top), 2 (middle), and 3 (bottom) in $\left[\mathrm{C}_{6} \mathrm{mim}\right][\mathrm{FAP}]$.

reversible nature with a peak-to-peak separation of approximately $80 \mathrm{mV}$, consistent with fast kinetics and indicating that any follow-up chemistry is relatively slow on the electrochemical time-scale. The oxidation in this case is tentatively attributed to a simultaneous two-electron process involving the rhenium centers, a behavior that was previously observed by dinuclear rhenium(I) species bridged by two halogen ligands and 1,2-diazine. ${ }^{7}$ Compared to our previously published results on trinuclear metallacalix[3] arene rhenium species bound by pyridyltetrazolato ligands, ${ }^{24}$ where the sequential oxidation of 


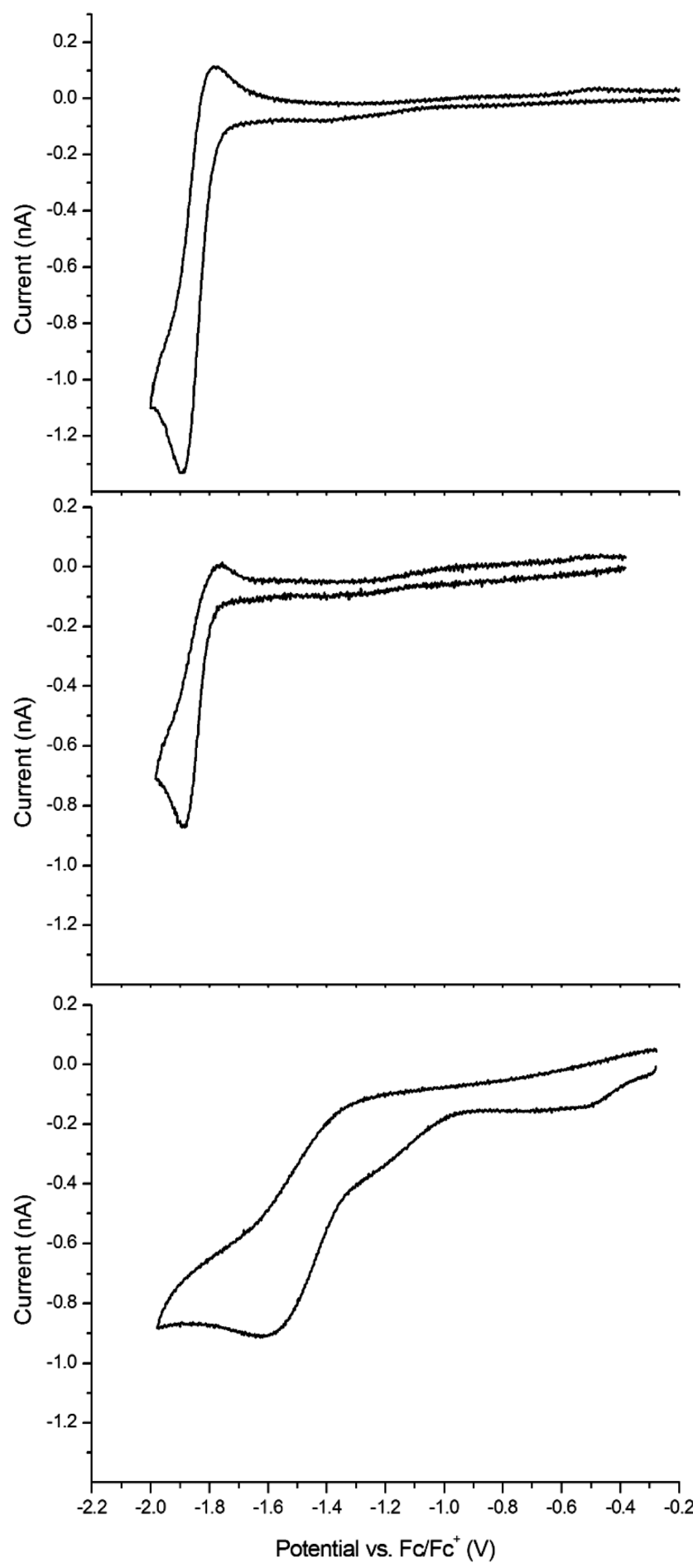

Figure 5. Reduction range of the cyclic voltammograms for solutions of 1 (top), 2 (middle), and 3 (bottom) in $\left[\mathrm{C}_{6} \mathrm{mim}\right]$ [FAP].

the rhenium centers was characterized by three reversible processes at progressively higher potentials, in this case only one wave is visible. The fact that the second oxidation is occurring almost simultaneously and not at higher potential for the negatively charged complex 3 could be attributed to the highly polar and ionic nature of the medium, where stabilization by solvation is more favorable to a cationic species (obtained via a two-electron oxidation from 3) rather than a neutral species (obtained via a one-electron oxidation from 3 ). ${ }^{7}$ However we also observed only a single oxidation peak in a less polar solvent, dichloromethane (results not shown). Therefore the lack of splitting of the two electron oxidation wave may more likely indicate a lack of interaction between the two Re centers.

The reduction peaks of complexes $\mathbf{1}$ and $\mathbf{2}$ have peak potentials at -1.89 and $-1.88 \mathrm{~V}$, respectively, and are attributed to reduction processes occurring on the pyridyltetrazole ligands. The reduction appears to be have a slightly reversible character with a peak-to-peak separation of approximately $110 \mathrm{mV}$, consistent with a moderately fast electrochemical step when compared to the separation of the $\mathrm{Fc} / \mathrm{Fc}^{+}$couple in ionic liquids $(90 \mathrm{mV})$, which is known to have fast kinetics. $^{41}$

For complex 3 the reduction peak is broader and appears to be characterized by a chemically irreversible process, and is ascribed to a reduction of the phenyltetrazolato ligand.

The differences in the peak currents for both the oxidation and reductions are attributed to the different concentration of the complexes in the ionic liquid solutions (see Experimental Section).

Computational Calculations. In order to further understand the electronic transitions of the complexes and validate the interpretation of the photophysical and electrochemical results, the absorption spectra of the complexes and the orbital contours were simulated with time-dependent density functional theory (TDDFT). The energy-minimized structures, obtained using the implicit solvent model (PCM), ${ }^{42}$ resulted in good agreement with the structural data obtained by X-ray diffraction: differences in the bond lengths were calculated within 0.01 and $0.1 \AA$, and differences in bond angle values were calculated between $0.9^{\circ}$ and $2^{\circ}$. These differences can be related to the presence of crystal packing effects in the X-ray determined structures, which are not present in the case of isolated molecules used in the calculations.

For complexes $\mathbf{1}$ and $\mathbf{2}$, the overall appearance of the simulated absorption spectra (reported in the Supporting Information along with the relative tables of calculated transitions) is in agreement with the experimental results. The lower energy band was determined to be composed by an envelope of transitions between the $\mathrm{HOMO}-n$ and $\mathrm{LUMO}+m$ orbitals $(n=0,1 ; m=0,1)$, with the main contributor being the HOMO-1 $\rightarrow$ LUMO transition (Figure 6). An analysis of the orbital contours for this transition reveals that the HOMO and HOMO-1 orbitals are mainly localized on the rhenium center and halogen ligand, whereas the LUMO and LUMO+1 are localized exclusively on the pyridyltetrazole ligand, with a higher contribution from the pyridine ring (especially in the case of the LUMO). This can be explained by the electron-rich nature of the tetrazole ring, and it is in agreement with orbital contours obtained from tricarbonyl rhenium(I) frangments bound to chelating pyridyltriazolato ligands. ${ }^{20-23}$ The calculations therefore agree with the MLCT character of the lowest excited state and suggest partial mixing with ligand-to-ligand charge transfer [LLCT, $\mathrm{X} \rightarrow \pi^{*}$ (pyridyltetrazole)].

In the case of the dinuclear complex 3 , the shoulder around $300 \mathrm{~nm}$ appearing in the experimental absorption spectrum seems to originate from transitions involving all the orbitals from the HOMO-5 to the LUMO+5, with the main contributor being the HOMO $\rightarrow$ LUMO +2 . All the HOMO $-n(n=0,5)$ orbitals are localized on the rhenium centers, whereas all the LUMO $+m(m=0,5)$ are distributed on the phenyltetrazolato ligand. Therefore, the calculations 

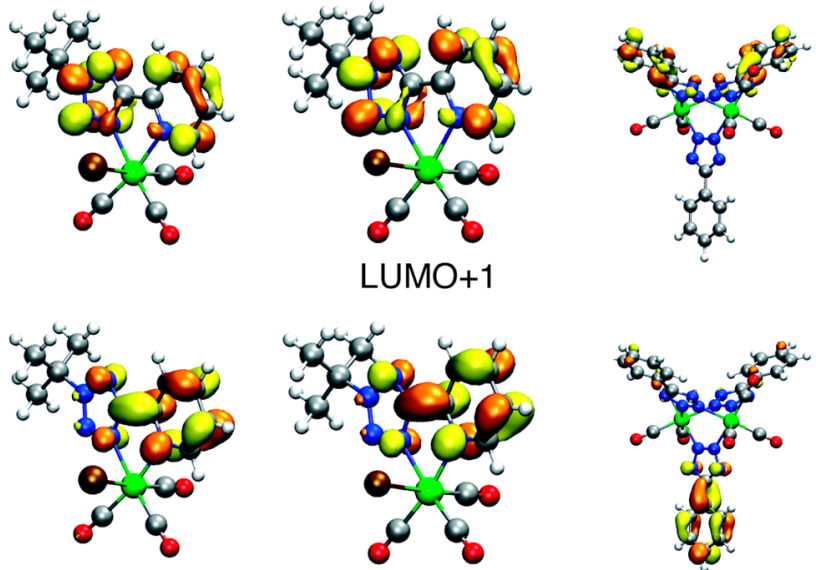

LUMO
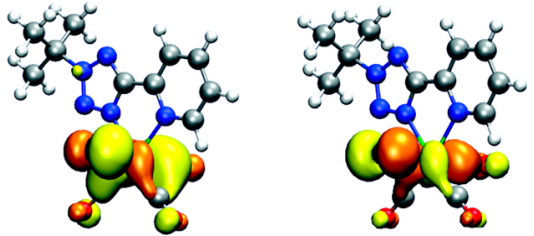

HOMO
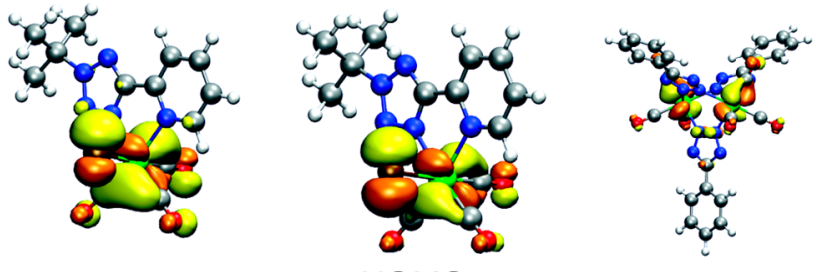

HOMO-1

Figure 6. Selected frontier orbital contours for 1 (left), 2 (center), and 3 (right).

corroborate that the lowest excited state of 3 has an MLCT character.

\section{CONCLUSIONS}

In conclusion, this work reports the synthesis of four tricarbonyl rhenium complexes bound to aryltetrazole ligands. The intimate chemical nature and charge of the tetrazole ligands directly influence the structures of the obtained species, which are either mononuclear complexes with bidentate tertbutylpyridyltetrazole, anionic dinuclear species bridged by three phenyltetrazolato ligands, or a dinuclear complex bridged by a tert-butylated phenyltetrazolato and two bromide ligands. The latter complex was found to be rather unstable in solution, and its complete purification and characterization was not possible, despite the successful growth of single crystals. The complexes obtained in this work emphasize how the neutral or anionic charge of the ligand reacting with the $\left[\operatorname{Re}(\mathrm{CO})_{5} \mathrm{X}\right]$ precursor might determine the exclusive dissociation of two $\mathrm{CO}$ ligands from the rhenium center or the concomitant dissociation of the anionic halogen ligand. The trend reported here is in agreement with previously reported structures of rhenium complexes. The photophysical properties of these complexes were investigated, clearly demonstrating that the tetrazolato ligand directly participates in the MLCT manifold. While complexes $\mathbf{1}$ and $\mathbf{2}$ possess photophysical properties that are typical of these species, complex 3 shows an extremely weak emission.
However, the reversible oxidation of 3 makes this dinuclear compound appealing in the construction of assemblies that exhibit photoinduced electron transfer.

\section{EXPERIMENTAL SECTION}

General Remarks. All reagents and solvents were purchased from Sigma Aldrich and used as received without further purification. 2$(1 H$-Tetrazol-5-yl)pyridine and 5-phenyl- $1 H$-tetrazole were synthesized according to previously published procedures. ${ }^{25}$ 2-(2-tertButyltetrazol-5-yl)pyridine and 5-phenyl-2-tert-butyltetrazole were also synthesized according to published procedures. ${ }^{16,43}$ Acidic alumina for column chromatography was of Brockmann I activity. Nuclear magnetic resonance spectra, consisting of ${ }^{1} \mathrm{H}$ and ${ }^{13} \mathrm{C}$, were recorded using a Bruker Avance 400 spectrometer $\left(400.1 \mathrm{MHz}\right.$ for ${ }^{1} \mathrm{H}$, $100 \mathrm{MHz}$ for ${ }^{13} \mathrm{C}$ ) at $300 \mathrm{~K} .{ }^{1} \mathrm{H}$ and ${ }^{13} \mathrm{C}$ chemical shifts were referenced to residual solvent signals. Infrared spectra were recorded in the solid state, using an attenuated total reflectance Perkin-Elmer Spectrum 100 FT-IR, equipped with a diamond stage. Compounds were scanned from 4000 to $650 \mathrm{~cm}^{-1}$. The intensities of the IR bands are reported as strong $(\mathrm{s})$, medium $(\mathrm{m})$, or weak $(\mathrm{w})$. Elemental analyses were obtained at the Central Science Laboratory, University of Tasmania, using a Thermo Finnigan EA 1112 Series Flash.

Photophysical Measurements. Absorption spectra were recorded at room temperature using a Perkin-Elmer Lambda $35 \mathrm{UV} /$ vis spectrometer. Uncorrected steady-state emission and excitation spectra were recorded on an Edinburgh FLSP920 spectrometer equipped with a $450 \mathrm{~W}$ xenon arc lamp, double excitation and single emission monochromators, and a Peltier-cooled Hamamatsu R928P photomultiplier tube. Emission and excitation spectra were corrected for source intensity (lamp and grating) and emission spectral response (detector and grating) by a calibration curve supplied with the instrument. According to the approach described by Demas and Crosby, ${ }^{44}$ luminescence quantum yields $\left(\Phi_{\mathrm{em}}\right)$ were measured in optically dilute solutions ( $\mathrm{OD}<0.1$ at excitation wavelength) obtained from absorption spectra on a wavelength scale [nm] and compared to the reference emitter by the following equation:

$$
\Phi_{x}=\Phi_{r}\left\lfloor\frac{A_{r}\left(\lambda_{r}\right)}{A_{x}\left(\lambda_{x}\right)}\right\rfloor\left[\frac{I_{r}\left(\lambda_{r}\right)}{I_{x}\left(\lambda_{x}\right)}\right\rfloor\left[\frac{n_{x}^{2}}{n_{r}{ }^{2}}\right]\left[\frac{D_{x}}{D_{r}}\right]
$$

where $A$ is the absorbance at the excitation wavelength $(\lambda), I$ is the intensity of the excitation light at the excitation wavelength $(\lambda), n$ is the refractive index of the solvent, $D$ is the integrated intensity of the luminescence, and $\Phi$ is the quantum yield. The subscripts $r$ and $x$ refer to the reference and the sample, respectively. The quantum yield determinations were performed at identical excitation wavelength for the sample and the reference, therefore canceling the $I\left(\lambda_{r}\right) / I\left(\lambda_{x}\right)$ term in the equation. All the Re complexes were measured against an airequilibrated water solution of $\left[\mathrm{Ru}(\mathrm{bpy})_{3}\right] \mathrm{Cl}_{2}$ used as reference $\left(\Phi_{r}=\right.$ 0.028). ${ }^{45}$ Emission lifetimes $(\tau)$ were determined with the single photon counting technique with the same Edinburgh FLSP920 spectrometer using pulsed picosecond LEDs (EPLED 295 or EPLED 360 , FWHM $<800 \mathrm{ps}$ ) as the excitation source, with repetition rates between $10 \mathrm{kHz}$ and $1 \mathrm{MHz}$, and the above-mentioned R928P PMT as detector. The goodness of fit was assessed by minimizing the reduced $\chi^{2}$ function and by visual inspection of the weighted residuals. To record the $77 \mathrm{~K}$ luminescence spectra, the samples were put in glass tubes ( $2 \mathrm{~mm}$ diameter) and inserted in a special quartz Dewar filled up with liquid nitrogen. The solvent (dichloromethane) used for the preparation of the solutions for the photophysical investigations was of spectrometric grade. The prepared solution was filtered through a $0.2 \mu \mathrm{m}$ syringe filter before measurement. Degassed samples were prepared by the freeze-pump-thaw technique. Experimental uncertainties are estimated to be $\pm 8 \%$ for lifetime determinations, $\pm 20 \%$ for quantum yields, and $\pm 2 \mathrm{~nm}$ and $\pm 5 \mathrm{~nm}$ for absorption and emission peaks, respectively.

Cyclic Voltammetry in Ionic Liquid. A gold microelectrode (made in house and kindly donated by the group of Professor Richard Compton at Oxford University, UK) was polished and modified with a 
section of disposable micropipet tip into which microliter quantities of the ionic liquid solvent can be placed. The electrode was then inserted into a "T-cell" apparatus as described elsewhere. ${ }^{46}$ A silver wire $(0.5$ $\mathrm{mm}$ diameter) was inserted from the top and acted as a combined counter and reference electrode. The T-cell was placed inside an aluminum Faraday cage and connected to a vacuum pump (Edwards ES50). The samples for electrochemistry were prepared by dissolving the required amount of rhenium complex in a minimal amount of dichloromethane and then adding this solution to the ionic liquid (1hexyl-3-methylimidazolium tris(pentafluoroethyl)trifluorophosphate, purchased from Merck Pty. Ltd., Australia, at ultra high purity electrochemical grade) in order to obtain a final concentration on the order of $10 \mathrm{mM}$. The solution was left in an open container to allow the dichloromethane to evaporate. A $40 \mu \mathrm{L}$ amount of this sample was transferred into the T-cell with the use of a micropipette. Experiments requiring the use of ferrocene followed the above procedure; however $10 \mu \mathrm{L}$ of a $10 \mathrm{mM}$ solution of ferrocene in acetonitrile was added into the T-cell apparatus along with the ionic liquid containing the rhenium complex. It is noted here that due to the small quantities of complexes/ferrocene and ionic liquid solvent used in this work, the exact concentrations used for electrochemistry are not known; although useful qualitative results can be obtained, the peak currents cannot be directly compared for a quantitative analysis. Cyclic voltammetry experiments were performed using a PGSTAT302N potentiostat (Eco-Chemie, Netherlands) interfaced to a PC with GPES (General Purpose Electrochemical System) software. The step potential was fixed at $0.01 \mathrm{~V}$. The potentials are referenced to an internal reference ferrocene/ferrocenium redox couple according to IUPAC recommendations ${ }^{47}$ and established in ionic liquids. ${ }^{46,48}$ Scans were performed using a potential window within the range -2.0 to 1.2 $\mathrm{V}$ reliant on the compound investigated. Reported potentials were obtained from a scan rate of $100 \mathrm{mV} \mathrm{s}^{-1}$

Computational Calculations. Time-dependent density functional theory calculations were performed with GAUSSIAN $09^{49}$ in order to calculate the absorption spectra for the title compound. Prior to these calculations, the structures were relaxed at the B3LYP level of theory. The Re atoms were treated with the Stuttgart-Dresden effective core potential, ${ }^{50}$ the Pople $6-311 \mathrm{G}^{* *}$ basis set was used for $\mathrm{C}, \mathrm{H}$, and $\mathrm{N}$ atoms, and the effect of the solvent was mimicked with the PCM solvation model, ${ }^{42}$ with parameters adequate for dichloromethane. The low-lying singlet-singlet excitation energies were calculated at the same level of theory, and the spectra were reproduced as the superposition of Gaussian functions with heights proportional to calculated intensities and a variance of $11 \mathrm{~nm}$.

Synthesis of 1. $\left[\mathrm{Re}(\mathrm{CO})_{5} \mathrm{Cl}\right](100 \mathrm{mg}, 0.27 \mathrm{mmol})$ and 2-(2-tertbutyltetrazol-5-yl)pyridine $(100 \mathrm{mg}, 0.49 \mathrm{mmol})$ were combined in toluene $(15 \mathrm{~mL})$ and stirred at reflux for $6 \mathrm{~h}$. The mixture was cooled, and the solvent removed under reduced pressure, yielding a yellow oil residue. The oil was dissolved in dichloromethane, and the addition of hexanes produced a yellow solid, which was filtered and washed with hexanes. Single crystals suitable for X-ray diffraction were grown by layering hexanes on a dichloromethane solution of 1 . Yield: $145 \mathrm{mg}$ (99\%). ${ }^{1} \mathrm{H} \mathrm{NMR}\left(\mathrm{CDCl}_{3}\right): \delta 9.08\left(\mathrm{~d},{ }^{n} J(\mathrm{H}, \mathrm{H})=5.4 \mathrm{~Hz}, 1 \mathrm{H} ; \mathrm{H} 6(\mathrm{py})\right)$, $8.28\left(\mathrm{~d},{ }^{n} J(\mathrm{H}, \mathrm{H})=8.1 \mathrm{~Hz}, 1 \mathrm{H} ; \mathrm{H} 3(\right.$ py $\left.)\right), 8.16-8.11$ (m, 1H; H(py)), 7.65-7.60 (m, 1H; $\mathrm{H}(\mathrm{py})), 1.88\left(\mathrm{~s}, 9 \mathrm{H} ; \mathrm{C}\left(\mathrm{CH}_{3}\right)_{3}\right)$ ppm; solvent peak at $\delta 5.29\left(\mathrm{~s}, \mathrm{CH}_{2} \mathrm{Cl}_{2}\right) \mathrm{ppm} .{ }^{13} \mathrm{C} \mathrm{NMR}\left(\mathrm{CDCl}_{3}\right): \delta 196.5(\mathrm{CO}), 194.7$ ( $\underline{\mathrm{CO}}), 188.5(\underline{\mathrm{CO}}), 166.1\left(\underline{\mathrm{CN}}_{4}\right), 153.9,145.2,139.8,128.3,124.0$, 68.4, $29.2 \mathrm{ppm}$; solvent peak at $\delta 55.6\left(\mathrm{CH}_{2} \mathrm{Cl}_{2}\right)$ ppm. IR: $\nu_{\max } 2021 \mathrm{~s}$ (CO), $1884 \mathrm{~s}(2$ overlapping $\mathrm{CO}) \mathrm{cm}^{-1}$. Anal. Calcd (\%) for 1. $\left(\mathrm{CH}_{2} \mathrm{Cl}_{2}\right): \mathrm{C} 28.31, \mathrm{H} 2.55, \mathrm{~N} 11.79$. Found: C 28.53, H 2.53, N 12.05 .

Synthesis of 2. $\left[\operatorname{Re}(\mathrm{CO})_{5} \mathrm{Br}\right](100 \mathrm{mg}, 0.25 \mathrm{mmol})$ and 2-(2-tertbutyltetrazol-5-yl)pyridine $(100 \mathrm{mg}, 0.49 \mathrm{mmol})$ were combined in toluene $(15 \mathrm{~mL})$ and stirred at reflux for $6 \mathrm{~h}$. The mixture was cooled, and the solvent removed under reduced pressure, yielding a yellow oil. The oil was dissolved in minimal dichloromethane and purified by column chromatography using alumina as the stationary phase and dichloromethane as eluent. The first fraction was collected and identified as the title compound. Single crystals suitable for X-ray diffraction were grown by layering hexanes on a dichloromethane solution of 2. Yield: $35 \mathrm{mg}(25 \%) .{ }^{1} \mathrm{H}$ NMR $\left(\mathrm{CDCl}_{3}\right): \delta 9.09$ (d, $\left.{ }^{n} J(\mathrm{H}, \mathrm{H})=4.8 \mathrm{~Hz}, 1 \mathrm{H} ; \mathrm{H} 6(\mathrm{py})\right), 8.29\left(\mathrm{~d},{ }^{n} J(\mathrm{H}, \mathrm{H})=7.8 \mathrm{~Hz}, 1 \mathrm{H}\right.$; H3(py)), 8.15-8.10 (m, 1H; H(py)), 7.64-7.59 (m, 1H; H(py)), $1.88\left(\mathrm{~s}, 9 \mathrm{H} ; \mathrm{C}\left(\mathrm{CH}_{3}\right)_{3}\right)$ ppm; solvent peak at $\delta 5.32\left(\mathrm{~s}, \mathrm{C}_{2} \mathrm{Cl}_{2}\right) \mathrm{ppm}$.

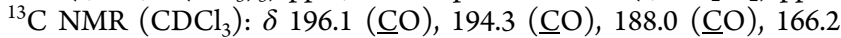
$\left(\underline{\mathrm{CN}}_{4}\right), 154.8,145.4,139.7,128.2,124.0,68.5,29.5 \mathrm{ppm}$; solvent peak at $\delta 55.6\left(\mathrm{CH}_{2} \mathrm{Cl}_{2}\right)$ ppm. IR: $\nu_{\max } 2020 \mathrm{~s}(\mathrm{CO}), 1881 \mathrm{~s}$ (2 overlapping CO) $\mathrm{cm}^{-1}$. Anal. Calcd (\%) for $2 \cdot 1.2\left(\mathrm{CH}_{2} \mathrm{Cl}_{2}\right): \mathrm{C} 26.08, \mathrm{H} 2.37, \mathrm{~N}$ 10.73. Found: C 25.82, H 2.22, N 11.12.

Synthesis of 3. $\left[\operatorname{Re}(\mathrm{CO})_{5} \mathrm{Br}\right](100 \mathrm{mg}, 0.25 \mathrm{mmol}), 5$-phenyl- $1 \mathrm{H}$ tetrazole $(53 \mathrm{mg}, 0.36 \mathrm{mmol})$ and triethylamine $(50 \mu \mathrm{L}, 0.36 \mathrm{mmol})$ were combined in toluene and stirred at reflux for $12 \mathrm{~h}$. The mixture was cooled and the solvent removed under reduced pressure. The residue was added to dichloromethane, and the white solid formed was filtered, washed with dichloromethane, and recrystallized from water, yielding the title compound. Yield: $60 \mathrm{mg}(45 \%) .{ }^{1} \mathrm{H}$ NMR $\left(d_{6}-\right.$ acetone): $\delta 8.15-8.10(\mathrm{~m}, 6 \mathrm{H} ; \mathrm{H}(\mathrm{ph})), 7.53-7.43(\mathrm{~m}, 9 \mathrm{H} ; \mathrm{H}(\mathrm{ph}))$, $3.42\left(\mathrm{q},{ }^{n} J(\mathrm{H}, \mathrm{H})=7.2 \mathrm{~Hz}, 6 \mathrm{H} ; \mathrm{NCH}_{2} \mathrm{CH}_{3}\right), 1.39\left(\mathrm{t},{ }^{n} J(\mathrm{H}, \mathrm{H})=7.2 \mathrm{~Hz}\right.$, 9H; $\left.\mathrm{NCH}_{2} \mathrm{CH}_{3}\right)$ ppm; solvent peak at $\delta 2.80\left(\mathrm{~s}, \underline{\mathrm{H}}_{2} \mathrm{O}\right) \mathrm{ppm} .{ }^{13} \mathrm{C} \mathrm{NMR}$ $\left(\mathrm{CDCl}_{3}\right): \delta 196.6(\underline{\mathrm{CO}}), 167.0\left(\underline{\mathrm{CN}}_{4}\right), 130.6,129.7,129.0,127.5$, 46.96, 9.03. IR: $\nu_{\max } 2024 \mathrm{~s}(\mathrm{CO}), 1901 \mathrm{~s}(\mathrm{CO}) \mathrm{cm}^{-1}$. Anal. Calcd (\%) for 3.2 $\left(\mathrm{H}_{2} \mathrm{O}\right)$ : C 35.58, H 3.17, N 16.34. Found: C 35.82, $\mathrm{H} 2.89, \mathrm{~N}$ 16.32 .

Synthesis of 4. $\left[\operatorname{Re}(\mathrm{CO})_{5} \mathrm{Br}\right](100 \mathrm{mg}, 0.25 \mathrm{mmol})$ and 5-phenyl2-tert-butyltetrazole $(54 \mathrm{mg}, 0.27 \mathrm{mmol})$ were combined in toluene and stirred at reflux for $12 \mathrm{~h}$. The mixture was cooled and the solvent removed under reduced pressure. Dichloromethane was added to the residual solid, and the mixture was filtered and washed with dichloromethane to give a white solid. Single crystals suitable for Xray diffraction were grown by layering hexanes on a solution of 4 in dichloromethane; the crop of crystals cocrystallized with an amorphous pale yellow solid. Yield (not optimized): $20 \mathrm{mg} .{ }^{1} \mathrm{H}$ NMR ( $d_{6}$-acetone $): \delta 8.15\left(\mathrm{~d},{ }^{n} J(\mathrm{H}, \mathrm{H})=6.8 \mathrm{~Hz}, 2 \mathrm{H} ; \mathrm{H}_{\text {ortho }}\right), 7.90-$ $7.50\left(\mathrm{~m}, 3 \mathrm{H} ; \mathrm{H}_{\text {meta }}\right.$ and $\left.\mathrm{H}_{\text {para }}\right), 1.76\left(\mathrm{~s}, 9 \mathrm{H} ; \mathrm{C}\left(\mathrm{C}_{3}\right)_{3}\right)$. Impurities appear to be present within the multiplet at $7.90-7.50 \mathrm{ppm}$, with integration corresponding to $3 \mathrm{H}$, and as a singlet at $1.82 \mathrm{ppm}$, with integration corresponding to $2 \mathrm{H}$. An accurate determination of the bulk composition by elemental analysis could not be obtained due to the presence of impurities.

X-ray Structural Determinations. Diffraction data were collected at $100(2) \mathrm{K}$ on an Oxford Diffraction Gemini diffractometer fitted with Mo $\mathrm{K} \alpha(\lambda=0.71073 \AA)$ radiation. Following analytical absorption corrections and solution by direct methods, the structures were refined against $F^{2}$ with full-matrix least-squares using the program SHELXL-97. ${ }^{51}$ All $\mathrm{H}$-atoms were added at calculated positions and refined by use of a riding model with isotropic displacement parameters based on those of the parent atoms. Anisotropic displacement parameters were employed throughout for the nonhydrogen atoms.

Crystal data for 1: $\mathrm{C}_{14} \mathrm{H}_{15} \mathrm{Cl}_{3} \mathrm{~N}_{5} \mathrm{O}_{3} \mathrm{Re} ; M=593.86$, monoclinic, space group $P 2_{1} / n, a=10.8488(5) \AA, b=11.4278(4) \AA, c=$ $16.6365(4) \AA, \beta=106.769(4)^{\circ}, V=1974.85(12) \AA^{3}, Z=4, \rho_{c}=1.997$ $\mathrm{Mg} / \mathrm{m}^{3}, \mu=6.583 \mathrm{~mm}^{-1}$. Reflections collected $=64078$, independent reflections $=10156(R($ int $)=0.0324), S=1.176 . \mathrm{R} 1=0.0293(I>$ $2 \sigma(I)), \mathrm{wR} 2=0.0596$ (all data). The tertiary butyl group was found to be disordered over two sets of sites with occupancies constrained to 0.5 after trial refinement.

Crystal data for 2: $\mathrm{C}_{14} \mathrm{H}_{14} \mathrm{BrCl}_{3} \mathrm{~N}_{5} \mathrm{O}_{3} \mathrm{Re} ; \mathrm{M}=672.76$, monoclinic, space group $P 2_{1} / c, a=8.6560(2) \AA, b=18.1418(2) \AA, c=13.2050(4)$ $\AA, \beta=92.829(3)^{\circ}, V=2071.13(8) \AA^{3}, Z=4, \rho_{\mathrm{c}}=2.158 \mathrm{Mg} / \mathrm{m}^{3}, \mu=$ $8.208 \mathrm{~mm}^{-1}$. Reflections collected $=53110$, independent reflections $=$ $13425(R($ int $)=0.0382), S=0.921$. R1 $=0.0229(I>2 \sigma(I))$, wR2 = 0.0403 (all data).

Crystal data for 3: $\mathrm{C}_{33} \mathrm{H}_{35} \mathrm{~N}_{13} \mathrm{O}_{8} \mathrm{Re}_{2} ; M=1114.14$, monoclinic, space group $C 2 / c, a=20.5571(5) \AA, b=12.1245(2) \AA, c=16.5533(4)$ $\AA, \beta=105.931(3)^{\circ}, V=3967.36(15) \AA^{3}, Z=4, \rho_{\mathrm{c}}=1.865 \mathrm{Mg} / \mathrm{m}^{3}, \mu=$ $6.162 \mathrm{~mm}^{-1}$. Reflections collected $=41968$, independent reflections $=$ $5755(R($ int $)=0.0366), S=0.971 . \mathrm{R} 1=0.0180(I>2 \sigma(I))$, wR2 $=$ 0.0428 (all data). The counterion was modeled as a $\mathrm{Et}_{3} \mathrm{NH}^{+}$cation with site occupancy constrained to 0.5 after trial refinement and charge 
balance considerations. Two peaks in the difference maps were modeled as water molecules with site occupancies also constrained to 0.5 .

Crystal data for 4: $\mathrm{C}_{18} \mathrm{H}_{16} \mathrm{Br}_{2} \mathrm{Cl}_{2} \mathrm{~N}_{4} \mathrm{O}_{6} \mathrm{Re} ; M=987.47$, monoclinic, space group $P 2_{1} / n, a=10.7387(2) \AA, b=16.7806(2) \AA, c=$ 14.5656(2) $\AA, \beta=104.820(2)^{\circ}, V=2537.43(7) \AA^{3}, Z=4, \rho_{c}=2.585$ $\mathrm{Mg} / \mathrm{m}^{3}, \mu=12.934 \mathrm{~mm}^{-1}$. Reflections collected $=63567$, independent reflections $=10334,(R($ int $)=0.0393), S=1.079$. R1 $=0.0209(I>2 \sigma(I)), \mathrm{wR} 2=0.0417$ (all data).

\section{ASSOCIATED CONTENT}

\section{S Supporting Information}

Bond lengths and angles tables, excitation and emission spectra at room temperature and $77 \mathrm{~K}$, simulated absorption spectra and list of calculated transitions, CIF files for the X-ray diffraction data. Crystallographic data for the structures reported in this paper have been deposited with the Cambridge Crystallographic Data Centre. CCDC 934711 (1), 934712 (2), 934713 (3), and 934714 (4) contain supplementary crystallographic data for this paper. This material is available free of charge via the Internet at http://pubs.acs.org.

\section{AUTHOR INFORMATION}

\section{Corresponding Author}

*E-mail: s.stagni@unibo.it; m.massi@curtin.edu.au.

\section{Notes}

The authors declare no competing financial interest.

\section{ACKNOWLEDGMENTS}

The work was supported by the Australian Research Council (DP0985481 and DP0986999). P.J.W. wishes to thank Curtin University for the Australian Postgraduate Award. Access to the facilities at the Centre for Microscopy, Characterisation and Analysis, University of Western Australia, is kindly acknowledged. P.R. and P.J.W. also acknowledge NCI for the provision of computer time.

\section{REFERENCES}

(1) Kirgan, R. A.; Sullivan, B. P.; Rillema, D. P. Top. Curr. Chem. 2007, 281, 45-100.

(2) Kumar, A.; Sun, S.; Lees, A. Top. Organomet. Chem. 2010, 29, 135 .

(3) Lo, K.; Hui, W.; Chung, C.; Tsang, K.; Ng, D.; Zhu, N.; Cheung, K. Coord. Chem. Rev. 2005, 249, 1434-1450.

(4) Fernández-Moreira, V.; Thorp-Greenwood, F. L.; Coogan, M. P. Chem. Commun. 2010, 46, 186-202.

(5) Chou, P.-T.; Chi, Y. Chem. Eur. J. 2007, 13, 380-395.

(6) Yersin, H.; Rausch, A. F.; Czerwieniec, R.; Hofbeck, T.; Fischer, T. Coord. Chem. Rev. 2011, 255, 2622-2652.

(7) Donghi, D.; D’Alfonso, G.; Mauro, M.; Panigati, M.; Mercandelli, P.; Sironi, A.; Mussini, P.; D’Alfonso, L. Inorg. Chem. 2008, 47, 42434255.

(8) Vlček, A.; Zális, S. Coord. Chem. Rev. 2007, 251, 258-287.

(9) Stufkens, D.; Vlček, A. Coord. Chem. Rev. 1998, 177, 127-179.

(10) Stufkens, D. J. Comments Inorg. Chem. 1992, 13, 359-385.

(11) Wrighton, M.; Morse, D. J. Am. Chem. Soc. 1974, 96, 998-1003.

(12) Vlček, A. Top. Organomet. Chem. 2010, 29, 73-114.

(13) Kober, E.; Caspar, J.; Lumpkin, R.; Meyer, T. J. Phys. Chem. 1986, 90, 3722-3734.

(14) Koike, K.; Okoshi, N.; Hori, H.; Takeuchi, K.; Ishitani, O.; Tsubaki, H.; Clark, I.; George, M.; Johnson, F.; Turner, J. J. Am. Chem. Soc. 2002, 124, 11448-11455.

(15) Werrett, M. V.; Chartrand, D.; Gale, J. D.; Hanan, G. S.; MacLellan, J. G.; Massi, M.; Muzzioli, S.; Raiteri, P.; Skelton, B. W.; Silberstein, M.; Stagni, S. Inorg. Chem. 2011, 50, 1229-1241.
(16) Wright, P. J.; Muzzioli, S.; Werrett, M. V.; Raiteri, P.; Skelton, B. W.; Silvester, D. S.; Stagni, S.; Massi, M. Organometallics 2012, 31, $7566-7578$.

(17) MaGee, K. D. M.; Wright, P. J.; Muzzioli, S.; Siedlovskas, C. M.; Raiteri, P.; Baker, M. V.; Brown, D. H.; Stagni, S.; Massi, M. Dalton Trans. 2013, 42, 4233-4236.

(18) Anderson, C. B.; Elliott, A. B. S.; Mcadam, C. J.; Gordon, K. C.; Crowley, J. D. Organometallics 2013, 32, 788-797.

(19) Anderson, C. B.; Elliott, A. B. S.; Lewis, J. E. M.; Mcadam, C. J.; Gordon, K. C.; Crowley, J. D. Dalton Trans. 2012, 41, 14625-14632.

(20) Obata, M.; Kitamura, A.; Mori, A.; Kameyama, C.; Czaplewska, J. A.; Tanaka, R.; Kinoshita, I.; Kusumoto, T.; Hashimoto, H.; Harada, M.; Mikata, Y.; Funabiki, T.; Yano, S. Dalton Trans. 2008, 3292-3300.

(21) Boulay, A.; Seridi, A.; Zedde, C.; Ladeira, S.; Picard, C.; Maron, L.; Benoist, E. Eur. J. Inorg. Chem. 2010, 5058-5062.

(22) Seridi, A.; Wolff, M.; Boulay, A.; Saffon, N.; Coulais, Y.; Picard, C.; Machura, B.; Benoist, E. Inorg. Chem. Commun. 2011, 14, 238242.

(23) Wolff, M.; Munoz, L.; François, A.; Carrayon, C.; Seridi, A.; Saffon, N.; Picard, C.; Machura, B.; Benoist, E. Dalton Trans. 2013, 42, 7019-7031.

(24) Wright, P. J.; Muzzioli, S.; Skelton, B. W.; Raiteri, P.; Lee, J.; Koutsantonis, G.; Silvester, D. S.; Stagni, S.; Massi, M. Dalton Trans. 2013, 42, 8188-8191.

(25) Koguro, K.; Oga, T.; Mitsui, S.; Orita, R. Synthesis 1998, 910914.

(26) Butler, R.; Garvin, V. J. Chem. Soc., Perkin Trans. 1 1981, 390393.

(27) Butler, R.; Garvin, V.; Lumbroso, H.; Liégeois, C. J. Chem. Soc., Perkin Trans. 2 1984, 721-725.

(28) Palazzi, A.; Stagni, S.; Bordoni, S.; Monari, M.; Selva, S. Organometallics 2002, 21, 3774-3781.

(29) Palazzi, A.; Stagni, S. J. Organomet. Chem. 2005, 690, 20522061.

(30) Mattes, R.; Weber, H. J. Organomet. Chem. 1979, 178, 191-196. (31) Mauro, M.; Panigati, M.; Donghi, D.; Mercandelli, P.; Mussini, P.; Sironi, A.; D'Alfonso, G. Inorg. Chem. 2008, 47, 11154-11165.

(32) Procopio, E. Q.; Mauro, M.; Panigati, M.; Donghi, D.; Mercandelli, P.; Sironi, A.; D'Alfonso, G.; De Cola, L. J. Am. Chem. Soc. 2010, 132, 14397-14399.

(33) Panigati, M.; Mauro, M.; Donghi, D.; Mercandelli, P.; Mussini, P.; De Cola, L.; D’alfonso, G. Coord. Chem. Rev. 2012, 256, 16211643.

(34) Stagni, S.; Orselli, E.; Palazzi, A.; De Cola, L.; Zacchini, S.; Femoni, C.; Marcaccio, M.; Paolucci, F.; Zanarini, S. Inorg. Chem. 2007, 46, 9126-9138.

(35) Maspero, A.; Galli, S.; Colombo, V.; Peli, G.; Masciocchi, N.; Stagni, S.; Barea, E.; Navarro, J. A. R. Inorg. Chim. Acta 2009, 362, 4340-4346.

(36) Ouellette, W.; Liu, H.; O'Connor, C. J.; Zubieta, J. Inorg. Chem. 2009, 48, 4655-4657.

(37) Luo, T.-T.; Tsai, H.-L.; Yang, S.-L.; Liu, Y.-H.; Yadav, R. D.; Su, C.-C.; Ueng, C.-H.; Lin, L.-G.; Lu, K.-L. Angew. Chem., Int. Ed. 2005, 44, 6063-6067.

(38) Silvester, D. S.; Uprety, S.; Wright, P. J.; Massi, M.; Stagni, S.; Muzzioli, S. J. Phys. Chem. C 2012, 116, 7327-7333.

(39) Bullock, J. P.; Carter, E.; Johnson, R.; Kennedy, A. T.; Key, S. E.; Kraft, B. J.; Saxon, D.; Underwood, P. Inorg. Chem. 2008, 47, 78807887.

(40) Kim, T. Y.; Elliott, A. B.; Shaffer, K. J.; McAdam, C. J.; Gordon, K. C.; Crowley, J. D. Polyhedron 2013, 52, 1391-1398.

(41) Barrosse-Antle, L. E.; Bond, A. M.; Compton, R. G.; O’Mahony, A. M.; Rogers, E. I.; Silvester, D. S. Chem. Asian J. 2010, 5, 202-230.

(42) Tomasi, J.; Mennucci, B.; Cammi, R. Chem. Rev. 2005, 105, 2999-3094.

(43) Downard, A.; Steel, P.; Steenwijk, J. Aust. J. Chem. 1995, 48, $1625-1642$.

(44) Demas, J. N.; Crosby, G. A. J. Phys. Chem. 1971, 75, 991-1024.

(45) Eaton, D. Pure Appl. Chem. 1988, 60, 1107-1114. 
(46) Silvester, D. S.; Wain, A. J.; Aldous, L.; Hardacre, C.; Compton, R. G. J. Electroanal. Chem. 2006, 596, 131-140.

(47) Gritzner, G.; Kuta, J. Pure Appl. Chem. 1984, 56, 461-466.

(48) Rogers, E. I.; Silvester, D. S.; Poole, D. L.; Aldous, L.; Hardacre, C.; Compton, R. G. J. Phys. Chem. C 2008, 112, 2729-2735.

(49) Frisch, M. J.; Frisch, M. J.; Trucks, G. W.; Schlegel, H. B.; Scuseria, G. E.; Robb, M. A.; Cheeseman, J. R.; Scalmani, G.; Barone, V.; Mennucci, B.; Petersson, G. A.; Nakatsuji, H.; Caricato, M.; Li, X.; Hratchian, H. P.; Izmaylov, A. F.; Bloino, J.; Zheng, G.; Sonnenberg, J. L.; Hada, M.; Ehara, M.; Toyota, K.; Fukuda, R.; Hasegawa, J.; Ishida, M.; Nakajima, T.; Honda, Y.; Kitao, O.; Nakai, H.; Vreven, T.; Montgomery, J. A., Jr.; Peralta, J. E.; Ogliaro, F.; Bearpark, M.; Heyd, J. J.; Brothers, E.; Kudin, K. N.; Staroverov, V. N.; Kobayashi, R.; Normand, J.; Raghavachari, K.; Rendell, A.; Burant, J. C.; Iyengar, S. S.; Tomasi, J.; Cossi, M.; Rega, N.; Millam, J. M.; Klene, M.; Knox, J. E.; Cross, J. B.; Bakken, V.; Adamo, C.; Jaramillo, J.; Gomperts, R.; Stratmann, R. E.; Yazyev, O.; Austin, A. J.; Cammi, R.; Pomelli, C.; Ochterski, J. W.; Martin, R. L.; Morokuma, K.; Zakrzewski, V. G.; Voth, G. A.; Salvador, P.; Dannenberg, J. J.; Dapprich, S.; Daniels, A. D.; Farkas, Ö.; Foresman, J. B.; Ortiz, J. V.; Cioslowski, J.; Fox, D. J. Gaussian09, Revision B.01; Wallingford, CT, 2009.

(50) Andrae, D.; Haeussermann, U.; Dolg, M.; Stoll, H.; Preuss, H. Theor. Chim. Acta 1990, 77, 123-141.

(51) Sheldrick, G. M. Acta Crystallogr. A 2008, 64, 112-122. 